\title{
THE LOCATION GNSS MODULES FOR THE COMPONENTS OF PROTEUS SYSTEM
}

\author{
K. Brzostowski, R. Darakchiev, A. Foks-Ryznar, P. Sitek \\ Space Research Centre of the Polish Academy of Sciences \\ Bartycka 18A, 00-716 Warsaw \\ e-mail: kroll@,cbk.waw.pl
}

\begin{abstract}
The Proteus system - the Integrated Mobile System for Counterterrorism and Rescue Operations is a complex innovative project. To assure the best possible localization of mobile components of the system, many different Global Navigation Satellite System (GNSS) modules were taken into account. In order to chose the best solution many types of tests were done. Full results and conclusions are presented in this paper.

The idea of measurements was to test modules in GPS Standard Positioning Service (SPS) with EGNOS system specification according to certain algorithms. The tests had to answer the question: what type of GNSS modules should be used on different components with respect to specific usage of Proteus system. The second goal of tests was to check the solution quality of integrated GNSS/INS (Inertial Navigation System) and its possible usage in some Proteus system components.
\end{abstract}

Keywords: GNSS, Navigation, Crisis management, INS, testing GNSS, GPS

\section{INTRODUCTION}

The aim of the Proteus project - the Integrated Mobile System for Counterterrorism and Rescue Operations - is to use innovative technologies in creation of a new integrated mobile system dedicated to firemen, counter-terrorists, Police and crisis management services. One of its achievements will be the use of mobile robots in activities dangerous for people. The whole operations will be managed from Mobile Command Centre. An Unmanned Aerial Vehicle will be used to survey the crisis zone. Additionally, Mobile Sensors Set will provide long-term static measurements of the operation site gathering the environmental data. The full list of the system components is as follows:

- Mobile Command Centre (MCC),

- Mobile Robot Operator Centre (MROC),

- Small Mobile Robot (SMR),

- Intervention Mobile Robot (IMR),

- Increased Functionality Mobile Robot (IFMR),

- Unmanned Aerial Vehicle (UAV),

- Portable Sensors Set (POSS,

- Personal Sensors Set (PESS),

- Robot Simulator (RS). 
The Space Research Centre of the Polish Academy of Sciences (SRC of PAS) develops the location modules for all mobile components of Proteus System except for UAV.

Series of tests was performed in the SRC of PAS. The main goal of the tests was to select the best GNSS (first series of testing) and GNSS/INS (second series) modules for the components of Proteus system. The tests consisted of static and kinematic part. The static test consisted of continuous determination of position on the fixed point for all receivers simultaneously (measuring time around 1 hour, interval 1 second). The same measuring conditions made the test very reliable. The measurements were done on two points with different radio-environment. The main goal of kinematic tests was to check how the modules work during move, in circums tances similar to the operation of mobile robots and vehicles of the Proteus system: open sky area, urban canyon, forest, etc.

\section{REQUIREMENTS FOR LOCATION MODULES}

The functional requirements for different location modules were specified precisely by final users. The technical restrictions of size and mass are dependent on system component. The additional requirement for all location modules is the simplicity in handling and quick readiness for use (Brzostowski K., 2010).

The vehicles, which are the Mobile Command Centre and the Mobile Robot Operator Centre, require the accuracy of Standard Positioning Service (SPS). The solution availability, mass, power consumption and size are of low priority. However the accurate knowledge of the north direction and inclination is required ( $+/-3$ degrees) in order to direct the satellite communication antenna properly.

For the robots we have defined two kinds of localization modules with different requirements: the modules for small robots (IMR and SMR) and the module for big robot IFMR.

The first kind of modules should secure the accuracy of SPS. The second kind of modules should secure better accuracy than the accuracy of SPS and the information about orientation (the north direction and inclination) with accuracy better than 3 degrees. The position and orientation of the system components is used in Mobile Command Centre to locate them and direct them to proper places.

The POST is a device deployed in a place where long-term static measurements of the operation site are necessary. It provides environmental information using sensors like thermal-camera, carbon monoxide sensor and chemical sensors. The POST requires a location module providing accuracy according to SPS standard. The localization information with environment parameters send to MCC gives better possibility to control the situation in endangered area.

The Personal Sensors Set (PESS) is an external module connected by wire interface to the radio-telephone. The PESS monitors the usage of the radio frequency and if it is possible transmits the localization and status data to the MCC. Inside the PESS module the localization module with SPS accuracy, the heart monitor, motion sensor and housekeeping sensors are installed. The difference between the location module for the PESS and the other modules is that the PESS uses an independent battery system, what determines low power consumption (less than $350 \mathrm{~mW}$ ).

Presented requirements show the need of usage of three types of modules:

- small, simple GNSS modules with standard SPS accuracy, high level of availability and very small and restrict power consumption, 
- more sophisticated GNSS modules with better solution quality (accuracy and precision) without any power consumption, weight and size limitations,

- very sophisticated GNSS modules with high solution quality with (Inertial Navigation Systems) INS option (not only position but also orientation parameters are required).

\section{THE LOCATION SENSORS}

The following location solutions are proposed to use in the project:

- Global Navigation Satellite Systems (GNSS),

- Inertial Navigation Systems (INS).

The GNSS are easy in usage and work all over the world, 24 hour per day and in all weather conditions. Nowadays the manufacturers develop high-sensitivity technology, offering possibility of reception of GNSS signal $30 \mathrm{~dB}$ weaker than in older generations and allowing the operation even in "light indoor" conditions. For example such receivers are: U-blox LEA 5-th and 6-th generations, SiRF IV or Mediatek MT 3328. In our tests we compared seven different GNSS modules: Fastrax, MTK (both working on Mediatek engine), Novatel OEMV-3G, Sirf Star III, U-blox LEA 4, U-blox LEA5 and U-blox LEA 6H (Table 1).

Table 1 The GNSS modules and antennas mounted on the base plate during first part of tests

\begin{tabular}{|c|c|c|}
\hline Antenna ID & GNSS module & Type of antenna \\
\hline ANT1 & Fastrax Mediatek MT 3318 & passive patch Q005 \\
\hline ANT2 & MTK Mediatek MT 3328 & 42GNSSSA-XT-1 \\
\hline ANT3 & Novatel OEMV-3 & passive patch Q005 \\
\hline ANT4 & Sirf III & passive patch Q001 \\
\hline ANT5 & U-blox LEA4 & passive patch Q001 \\
\hline ANT6 & U-blox LEA5 & \\
\hline
\end{tabular}

To improve location module's performance, INS sensors are included into the design. They allow location of the objects when the GNSS signal is lost. Unfortunately, the INS units lose their accuracy as time runs. This is because the position in calculated by double integration of acceleration and such an operation cumulates errors. For the tests we have used Septentrio and Xsens GNSS/INS modules (Table 2).

Table 2 The GNSS and GNSS/INS modules and antennas mounted on the base plate during second part of tests.

\begin{tabular}{|c|c|c|}
\hline Antenna ID & GNSS or GNSS/INS module & Antenna type \\
\hline ANT7 & U-blox LEA6 & passive patch Q001 \\
\hline ANT8 & Septentrio AsteRx-2i & MTi-28A53G35 \\
\hline INS1 & Septentrio AsteRx-2i & active patch antenna AE006 \\
\hline ANT9 & Xsens MTi-G & MTi-G-28A83G25 \\
\hline INS2 & Xsens MTi-G & \\
\hline
\end{tabular}

The first six GNSS modules were tested simultaneously in April 2010, the last GNSS module (U-blox LEA 6H) was tested with GNSS/INS modules in January 2011.

The parameters of tested localization sensors described by their manufacturers can be found in Table 3. It is clearly visible that the highest-performance GNSS modules Novatel, Septentrio and Xsens have the highest power consumption. Additionally the Novatel and Septentrio modules give possibility of support from GLONASS satellites. The mechanical dimensions for this modules are the biggest too. Comparing sensitivity all modules (excluding U-blox LEA4) are on the similar level. 
Table 3 Technical data comparison GNSS and GNSS/INS modules

\begin{tabular}{|c|c|c|c|c|c|c|c|c|c|}
\hline Manufacturer & $\begin{array}{c}\text { Fastrax } \\
{[1]}\end{array}$ & $\begin{array}{c}\text { MTK } \\
{[2]}\end{array}$ & $\begin{array}{c}\text { Modulestek } \\
{[3]}\end{array}$ & $\begin{array}{c}\text { U-bl ox } \\
{[4]}\end{array}$ & $\begin{array}{c}\text { U-bl ox } \\
{[5]}\end{array}$ & $\begin{array}{c}\text { Novatel } \\
{[6]}\end{array}$ & $\begin{array}{c}\text { U-blox } \\
\text { [7] }\end{array}$ & $\begin{array}{c}\text { Septentrio } \\
{[8]}\end{array}$ & $\begin{array}{c}\text { Xsens } \\
{[9]}\end{array}$ \\
\hline GNSS chip & $\begin{array}{l}\text { Mediatek } \\
\text { MT } 3318\end{array}$ & $\begin{array}{c}\text { Mediat } \\
\text { ek MT } \\
3328\end{array}$ & Sirf Star III & LEA 4P & LEA $5 \mathrm{H}$ & OEMV-3G & LEA $6 \mathrm{H}$ & AsteRx $2 \mathrm{i}$ & MTi-G \\
\hline GNSS signal & C/A, L1 & $\begin{array}{c}\mathrm{C} / \mathrm{A}, \\
\mathrm{L} 1\end{array}$ & C/A, L1 & C/A, L1 & C/A, L1 & L1, L2, L5 & L1, C/A, & $\mathrm{L} 1, \mathrm{~L} 2, \mathrm{C} / \mathrm{A}$ & L1, C/A \\
\hline Channels & $\begin{array}{c}32 \mathrm{~L} 1 \\
2 \mathrm{SBAS}\end{array}$ & $\begin{array}{c}66 \mathrm{~L} 1 \\
2 \\
\text { SBAS }\end{array}$ & $\begin{array}{c}20 \mathrm{~L} 1 \\
2 \mathrm{SBAS}\end{array}$ & $\begin{array}{c}16 \mathrm{~L} 1 \\
2 \mathrm{SBAS}\end{array}$ & $\begin{array}{c}50 \mathrm{~L} 1 \\
2 \mathrm{SBAS}\end{array}$ & $\begin{array}{c}14 \mathrm{~L} 1, \\
14 \mathrm{~L} 2,6 \mathrm{~L} 5 \\
12 \mathrm{GL} 1,12 \\
\text { GL2 } \\
2 \text { SBAS } \\
\end{array}$ & $\begin{array}{c}50 \mathrm{~L} 1 \\
2 \mathrm{SBAS}\end{array}$ & $\begin{aligned} & 136 \text { (GPS, } \\
& \text { GLONASS) } \\
&+3 \text { (SBAS) }\end{aligned}$ & $50 \mathrm{~L} 1$ \\
\hline $\begin{array}{l}\text { Additional } \\
\text { functions }\end{array}$ & - & - & - & - & $\begin{array}{l}\text { Galileo } \\
\text { ready L1 }\end{array}$ & - & $\begin{array}{c}\text { A-GPS, } \\
\text { SBAS, } \\
\text { Galileo } \\
\text { ready L1 }\end{array}$ & $\begin{array}{c}\text { Integrated } \\
\text { IMU } \\
\text { RTK, DGPS, } \\
\text { SBAS } \\
\end{array}$ & $\begin{array}{l}\text { Galileo } \\
\text { ready L1 }\end{array}$ \\
\hline $\begin{array}{l}\text { Sensitivity } \\
\text { ac quisition } \\
\text { (dB m) } \\
\text { tr acking } \\
\text { (dB m) }\end{array}$ & $\begin{array}{l}-146 \\
-159\end{array}$ & $\begin{array}{l}-148 \\
-165\end{array}$ & $\begin{array}{l}-147 \\
-158\end{array}$ & $\begin{array}{l}-140 \\
-150\end{array}$ & $\begin{array}{l}-144 \\
-160\end{array}$ & no data & $\begin{array}{l}-147 \\
-160\end{array}$ & no data & no data \\
\hline $\begin{array}{l}\text { Data Rate } \\
(\mathrm{Hz})\end{array}$ & 5 & 10 & 5 & 4 & 4 & 20 & $\begin{array}{l}\text { 5(ROM), } \\
2 \text { (Flash) }\end{array}$ & up to 50 & 4 \\
\hline $\begin{array}{l}\text { Ac quisition } \\
\text { cold (s) } \\
\operatorname{warm}(\mathrm{s}) \\
\operatorname{hot}(\mathrm{s}) \\
\end{array}$ & $\begin{array}{c}36 \\
33 \\
1\end{array}$ & $\begin{array}{c}34 \\
33 \\
1\end{array}$ & $\begin{array}{c}42 \\
38 \\
1\end{array}$ & $\begin{array}{c}34 \\
33 \\
<3.5\end{array}$ & $\begin{array}{l}29 \\
29 \\
<1\end{array}$ & $\begin{array}{c}60 \\
35 \\
1\end{array}$ & $\begin{array}{c}28 \\
28 \\
1\end{array}$ & $\begin{array}{l}45 \\
20 \\
1.2\end{array}$ & $\begin{array}{c}29 \\
29 \\
1\end{array}$ \\
\hline $\begin{array}{l}\text { Accuracy } \\
\text { single } \\
\text { point(m)/ } \\
\text { SBAS (m) } \\
\end{array}$ & $3.0 / 2.5$ & $\begin{array}{c}2.5 / \\
2.0\end{array}$ & $3 /<2.5$ & $\begin{array}{r}2.5 / \\
2.0\end{array}$ & $\begin{array}{c}2.5 / \\
2.0\end{array}$ & $\begin{array}{c}1.5 / \\
1.2\end{array}$ & $\begin{array}{l}<2.5 / \\
<2.0\end{array}$ & $\begin{array}{l}1.0,1.6^{*} / \\
0.5,0.7^{*}\end{array}$ & 2.5 \\
\hline $\begin{array}{l}\text { Operating } \\
\text { temperature } \\
\left({ }^{\circ} \mathrm{C}\right) \\
\end{array}$ & $-30^{\circ}+85$ & $-40+85$ & $-40+85$ & $-40+85$ & $-40+85$ & $-40+85$ & $-40+85$ & $\begin{array}{c}-40+70 \\
-20+60 \\
(\mathrm{IMU}) \\
\end{array}$ & $-40+85$ \\
\hline Dimension & $\begin{array}{c}18.8 \mathrm{x} \\
16.2 \mathrm{x} \\
2.5 \mathrm{~mm}\end{array}$ & $\begin{array}{c}18.8 \mathrm{x} \\
16.2 \mathrm{x} \\
2.5 \mathrm{~mm}\end{array}$ & $\begin{array}{c}19.3 \times 20 \times \\
2.6 \mathrm{~mm}\end{array}$ & $\begin{array}{c}17 \times 22.4 \times \\
3 \mathrm{~mm}\end{array}$ & $\begin{array}{c}17 \times 22.4 \times \\
3 \mathrm{~mm}\end{array}$ & $\begin{array}{c}85 \times 125 \times \\
13 \mathrm{~mm}\end{array}$ & $\begin{array}{c}17 \times 22.4 \times \\
2.4 \mathrm{~mm}\end{array}$ & $\begin{array}{c}60 \times 90 \mathrm{~mm} \\
(\mathrm{OEM}) \\
58 \times 58 \times \\
22 \mathrm{~mm} \\
(\mathrm{IMU})\end{array}$ & $\begin{array}{c}58 \times 58 \times \\
33 \mathrm{~mm}\end{array}$ \\
\hline $\begin{array}{l}\text { Power } \\
\text { consumption } \\
\text { (mW) }\end{array}$ & $\begin{array}{l}90 \\
@ 3 \mathrm{~V}\end{array}$ & $\begin{array}{c}160 \\
@ 3.3 \mathrm{~V}\end{array}$ & $\begin{array}{c}225 \\
@ 3.3 \mathrm{~V}\end{array}$ & $\begin{array}{c}108 \\
@ 3 \mathrm{~V}\end{array}$ & $\begin{array}{c}130 \\
@ 2.7-3.6 \mathrm{~V}\end{array}$ & $\begin{array}{c}2500 \\
\text { (a) } 4.5-18 \mathrm{~V}\end{array}$ & $\begin{array}{c}115 \\
@ 3 \mathrm{~V}\end{array}$ & $\begin{array}{c}2500 \\
\text { @9-30V }\end{array}$ & $\begin{array}{c}910 \\
@ 5-30 \mathrm{~V}\end{array}$ \\
\hline
\end{tabular}

\section{PLAN OF TESTS}

Static tests should show real accuracy, precision and resistance to multipath effects of tested modules in natural environmental conditions.

The measurements were done on two specified points called P1 and P2 (Fig. 1). Subsequently precise reference measurements of P1 and P2 positions were done (with the high accuracy geodetic receiver in static mode) for comparison with tested GNSS and GNSS/INS module's results (Table 4).

The P1 point was located in front of the SRC of PAS building, $30 \mathrm{~m}$ from it, giving very good satellite visibility. Main goal of this test was to check the accuracy and precision of tested modules.

The second point P2 is located in a place where two sides (north-west and south-west) are almost completely obscured by the near building. In the north there is a wall which covers the horizon below 15 degrees. Only east and south-east side were almost clear with some trees. In this test, first of all the tough environmental conditions (poor satellite constellation 
geometry, small number of available satellites, big multipath effect) impact on the localization solution quality was studied.

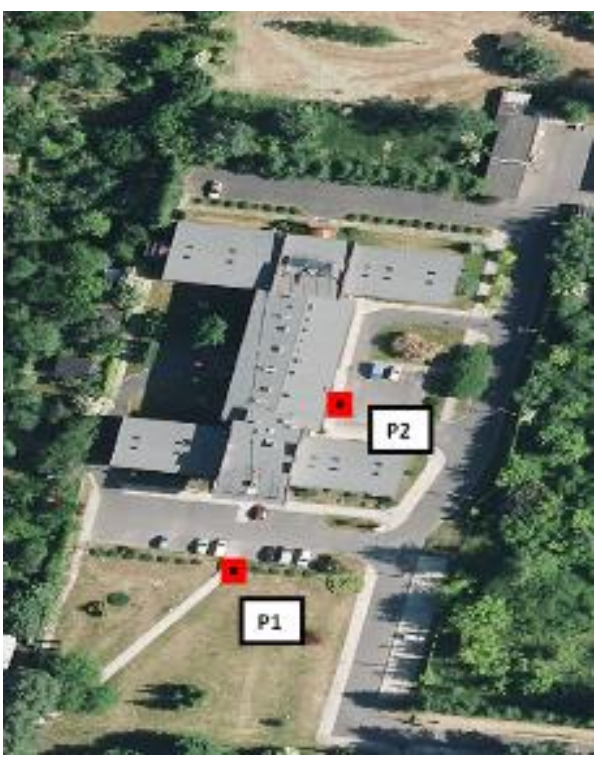

Table 4 Coordinates of points P1 and P2

\begin{tabular}{|l|l|}
\hline No & $\begin{array}{c}\text { Latitude (B) } \\
\text { Longitude (L) }\end{array}$ \\
\hline \multirow{2}{*}{ P1 } & $52^{\circ} 12^{\prime} 50,3722^{\prime} \mathrm{N}$ \\
& $21^{\circ} 04^{\prime} 02,7877^{\prime} \mathrm{E}$ \\
\hline \multirow{2}{*}{ P2 } & $52^{\circ} 12^{\prime} 51,89899^{\prime \prime} \mathrm{N}$ \\
& $21^{\circ} 04^{\prime} 03,74399^{\prime} \mathrm{E}$ \\
\hline
\end{tabular}

Fig. 1 Localization of points P1 and $\mathrm{P} 2$ in SRC of PAS area (figure is north oriented)

The kinematic tests could be divided into three parts:

1. Test on a mobile platform, in small area around SRC of PAS, with low speed, in various terrain with different observation conditions. Test had to simulate the localization of mobile robots in different field situations (Figure 2). The main parts of this measurement were: passing under fire escapes (with very low number of visible satellites and big multipath effect), driving a narrow path along high 5-floor buildings (urban canyon simulation), drive along public road with some trees around (standard field case). The length of the test was around 45 minutes, measuring interval 1 second for GNSS and 0,1 second for GNSS/INS.

2. Street test on a car (antenna was placed on the roof of the car) in normal city traffic. Test had to imitate the localization of Proteus system cars (MCC and MROC). The test involved driving through a wide road with almost fully open sky horizon, passing the low houses residential, city canyon and forest. The whole test lasted two hours. The measuring interval was 1 second for GNSS and 0.1 second for GNSS/INS.

3. Indoor test. The test was inside SRC of PAS building on two highest floors. During this test only four receivers with the highest sensitivity were taken into account. 


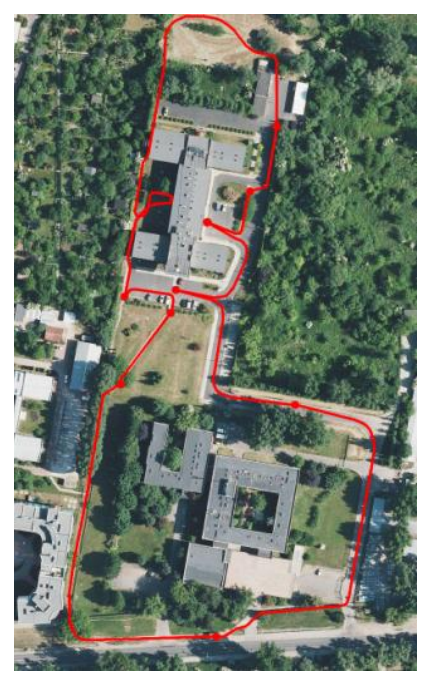

Fig. 2 The reference route of one of the kinematic tests (SRC of PAS area)

During all tests antennas were mounted on a plastic flat base plate (Fig. 3 and 4). In static tests the base plate was placed on a geodetic tripod $1 \mathrm{~m}$ above the point P1 and P2 with known position and in kinematic tests the plate with antennas was on a mobile platform or on a car roof.

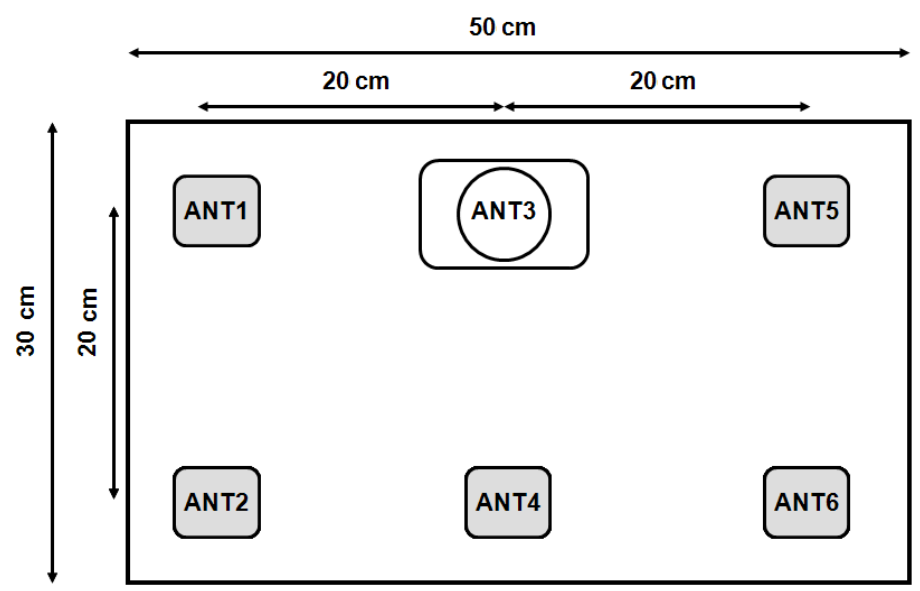

Fig. 3 GNSS antennas location on the plastic base plate during first part of tests (only GNSS modules).

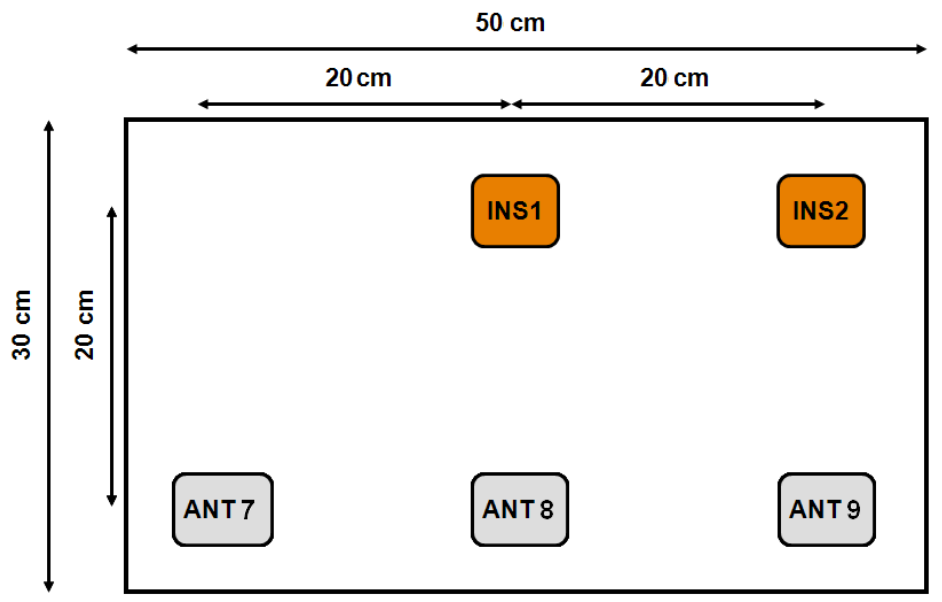

Fig. 4 GNSS antennas and INS modules location on the plastic base plate during second part of tests. 


\section{TESTS}

\section{Measurements on $P 1$ point}

The measurement interval for all modules except for Xsens and Septentrio (GNSS/INS modules) was $1 \mathrm{~s}(1 \mathrm{~Hz})$. For GNSS/INS modules the interval was $10 \mathrm{~ms}(100 \mathrm{~Hz})$ that is why the measurement time for these modules was shortened.

The first test (only GNSS modules) took place on 26.04.2010 between 11:27 and 12:20 UTC. The second test on the point P1 (with the INS modules) took place on 4.01.2011 between 11:14 and 11:31 UTC (Figure 5).
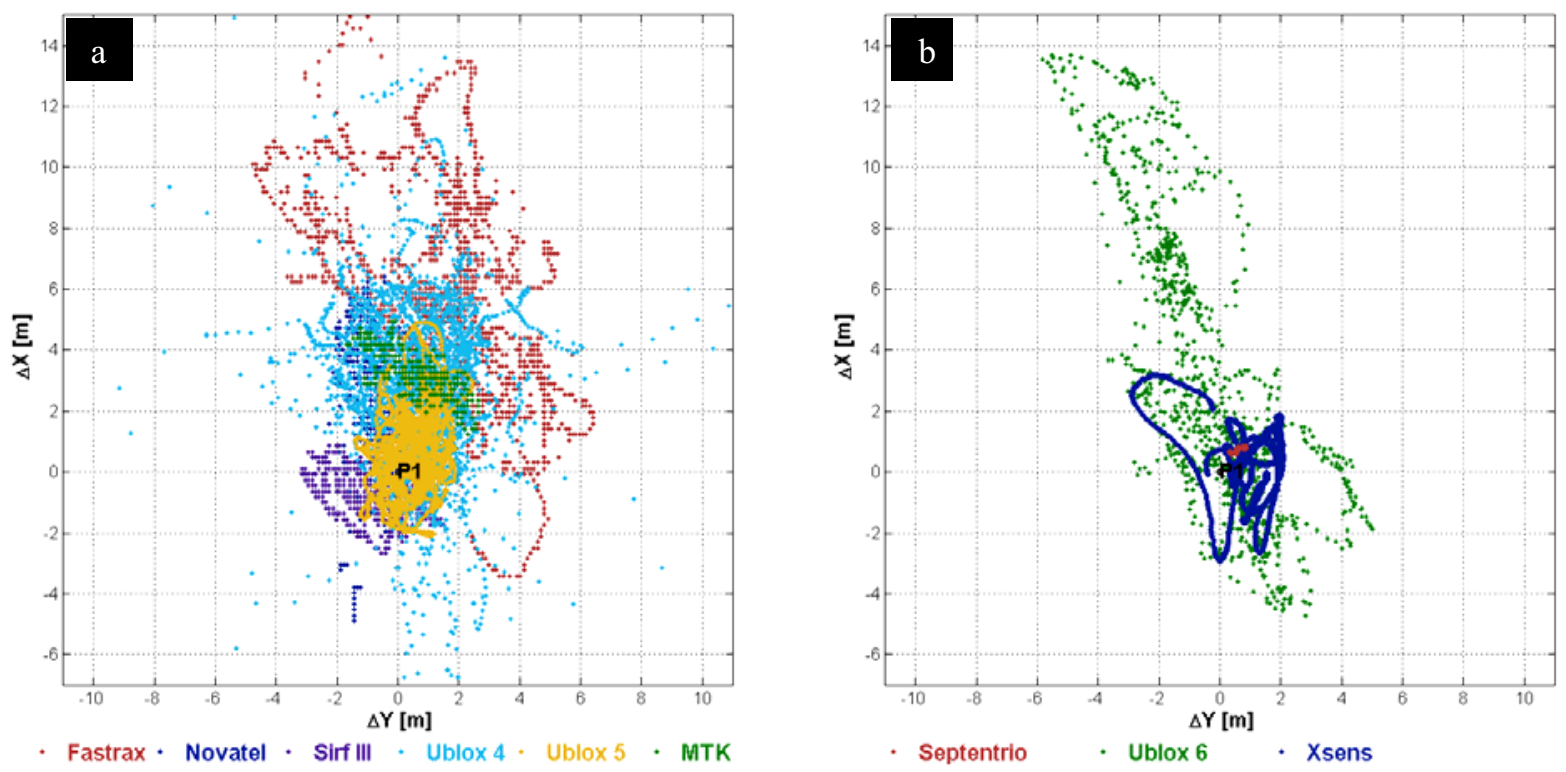

Fig. 5 Traces of the horizontal components of the localization solutions of the tested receivers with respect to reference position of point P1, (a) - first test, (b) - second test

During the first test on the P1 point all modules gave $100 \%$ availability of the localization solution. The average number of used satellites was about 9 (minimum 7.73 for Novatel and maximum 9.42 for U-blox LEA5 and Sirf III). The very high number of used satellites not in all cases gave high quality of computed position (Fig. 6).

Despite the outstanding sensitivity (the best DOPs and usage of over 9 satellites) the Fastrax receiver achieves the worst position solution. The results were so bad because the receiver used all signals in view (the strong direct one and also the weak signals with big multipath). The static tests on P1 point revealed that the best GNSS receiver was U-blox LEA $5 \mathrm{H}$ with the very small $\mathrm{X}$ and $\mathrm{Y}$ shifts $(0.68 \mathrm{~m}$ and $0.44 \mathrm{~m})$ and standard deviation at level around $1 \mathrm{~m}$. All statistics are presented in the table 5. 

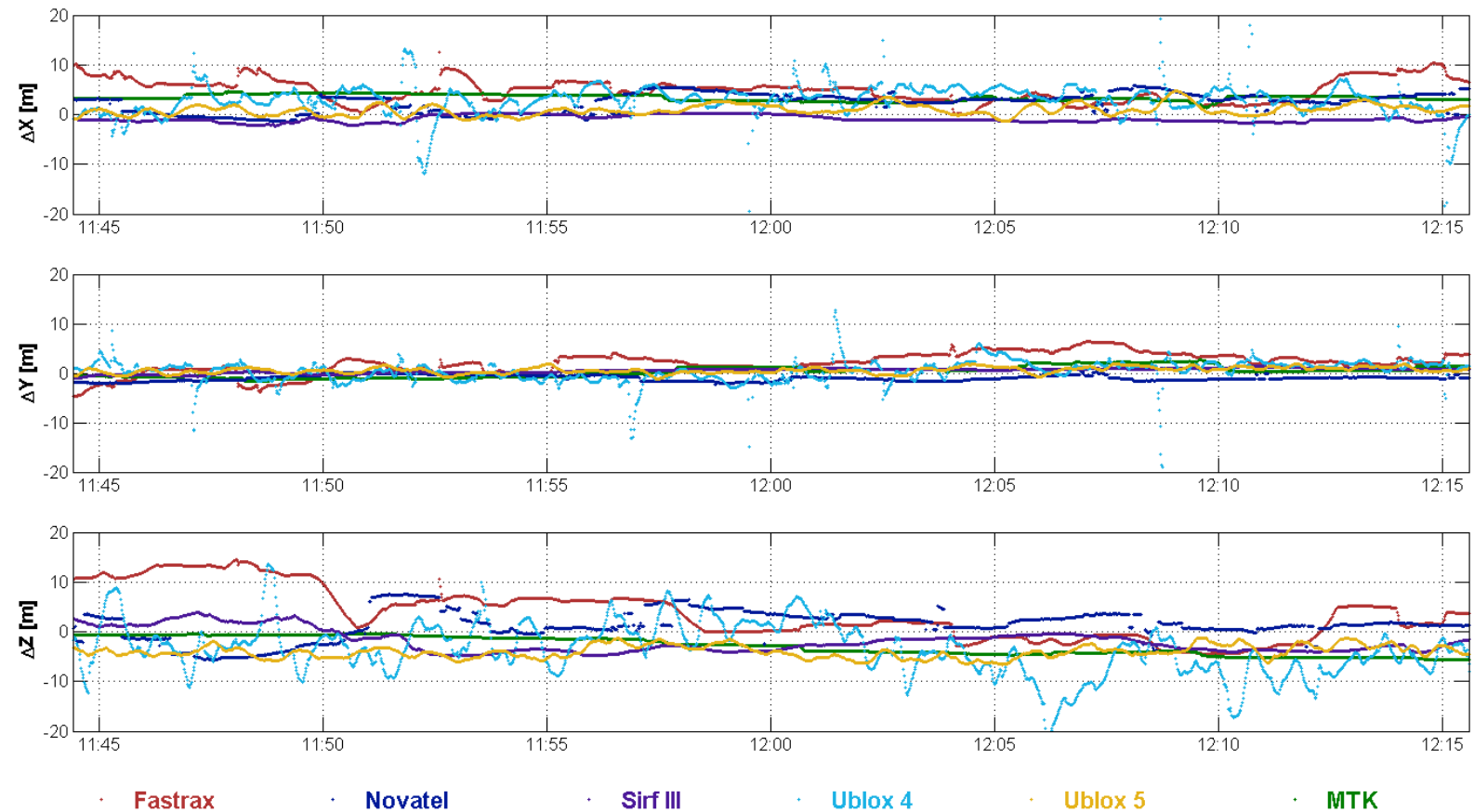

Fig. 6 Variability in time of the coordinates $X, Y, Z$ with respect to the reference position of point $\mathrm{P} 1$ during the first test

Table 1 Numerical comparison of the tested receivers on point P1 (values much better than rest are bolded)

\begin{tabular}{|c|c|c|c|c|c|c|}
\hline $\begin{array}{c}\text { Receiver } \\
\text { Parameter }\end{array}$ & Fastrax & MTK & Novatel & Sirf III & U-blox 4 & U-blox 5 \\
\hline $\begin{array}{c}\text { GNSS } \\
\text { module }\end{array}$ & $\begin{array}{c}\text { Mediatek } \\
\text { MT 3318 }\end{array}$ & $\begin{array}{c}\text { Mediatek } \\
\text { MT 3328 }\end{array}$ & $\begin{array}{c}\text { OEMV- } \\
3 G\end{array}$ & $\begin{array}{c}\text { Sirf Star } \\
\text { III }\end{array}$ & LEA 4P & LEA 5H \\
\hline $\begin{array}{c}\text { Epoch } \\
\text { without } \\
\text { solution [\%] }\end{array}$ & 0.00 & 0.00 & 0.00 & 0.00 & 0.00 & 0.00 \\
\hline $\begin{array}{c}\text { Average } \\
\text { number of } \\
\text { satellites }\end{array}$ & 9.09 & 9.30 & 7.73 & $\mathbf{9 . 4 2}$ & 8.66 & $\mathbf{9 . 4 2}$ \\
\hline PDOP (avg.) & $\mathbf{1 . 6 3}$ & 1.77 & 2.37 & 1.74 & 2.38 & 1.79 \\
\hline HDOP (avg.) & $\mathbf{0 . 9 1}$ & $\mathbf{0 . 9 0}$ & 1.18 & $\mathbf{0 . 8 7}$ & 1.19 & $\mathbf{0 . 9 0}$ \\
\hline VDOP (avg.) & $\mathbf{1 . 3 4}$ & 1.52 & 2.06 & 1.48 & 2.05 & 1.54 \\
\hline X shift [m] & 5.91 & 3.28 & 1.87 & $\mathbf{- 0 . 8 3}$ & 2.68 & $\mathbf{0 . 6 8}$ \\
\hline Y shift [m] & 1.65 & $\mathbf{0 . 4 9}$ & -0.93 & $\mathbf{- 0 . 1 3}$ & 0.90 & $\mathbf{0 . 4 4}$ \\
\hline Z shift [m] & 7.19 & -3.07 & $\mathbf{- 0 . 4 1}$ & -1.14 & -4.70 & -4.63 \\
\hline $\begin{array}{c}\text { Std. } \\
\text { deviation X } \\
\text { [m] }\end{array}$ & 3.12 & $\mathbf{0 . 6 4}$ & 2.42 & $\mathbf{0 . 6 9}$ & 3.41 & 1.28 \\
\hline $\begin{array}{c}\text { Std. } \\
\text { deviation Y } \\
\text { [m] }\end{array}$ & 2.22 & 1.02 & $\mathbf{0 . 5 2}$ & 1.07 & 3.93 & $\mathbf{0 . 6 9}$ \\
\hline $\begin{array}{c}\text { Std. } \\
\text { deviation Z } \\
\text { [m] }\end{array}$ & 8.03 & 2.28 & $\mathbf{2 . 8 2}$ & 3.41 & 5.46 & $\mathbf{1 . 3 8}$ \\
\hline
\end{tabular}


During the second test on P1 point all modules gave 100\% availability of the localization solution and the number of used satellites for position computation was from 8 to 10 .

In the figure 7 it can be easily seen that usage of integrated GNSS/INS modules give much better solution in particular when measurement precision is considered.

For U-blox LEA6 module (only GPS), standard for this system localization characteristics can be observed: accuracy up to $13 \mathrm{~m}$ and precision ( 2 sigma parameter) around $7 \mathrm{~m}$.

Xsens module, which used GPS and INS units, produced considerably better solution: accuracy $-3 \mathrm{~m}$ and precision $1.5 \mathrm{~m}$.
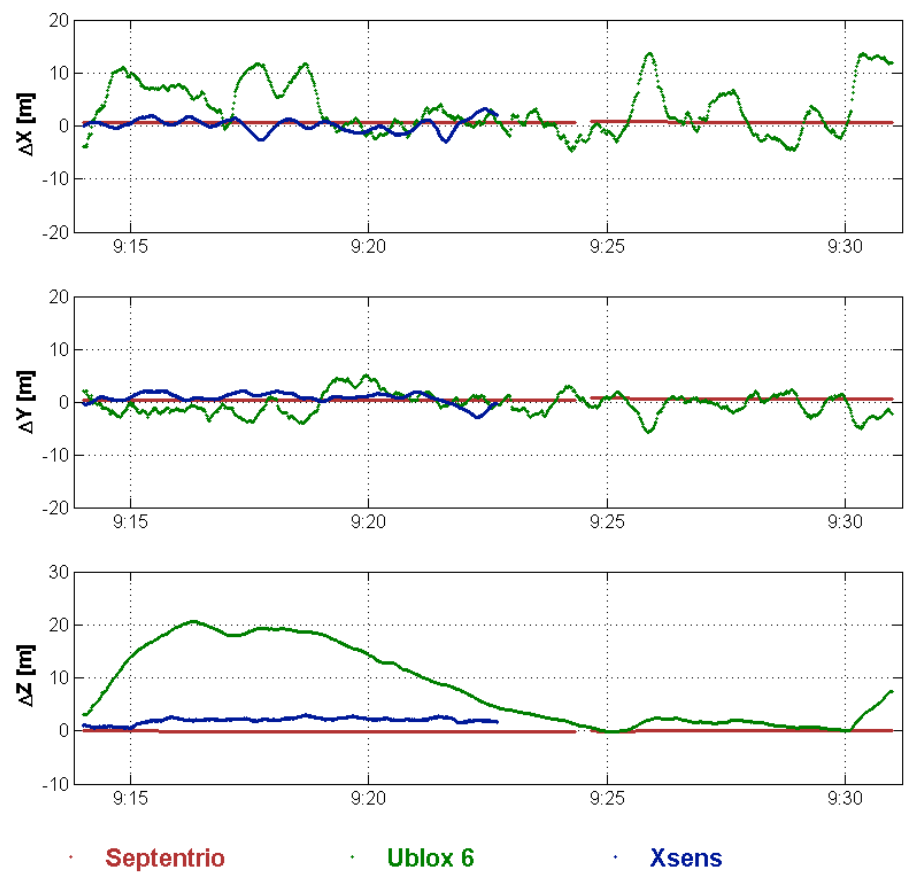

Fig. 7 Variability in time of the coordinates $\mathrm{X}, \mathrm{Y}, \mathrm{Z}$ with respect to the reference position of point P1 during the second test

Definitely Septentrio (GPS + INS module) achieved the best localization solution results on $\mathrm{P} 1$ point. Maximum error was around $1 \mathrm{~m}$ and the measurements precision was $30 \mathrm{~cm}$.

Despite the fact that Xsens and Septentrio use exactly the same INS unit, the significant difference between the results of those modules was discovered. This discrepancy proves the importance of used software.

In figure 8 are shown the results of comparison of Septentrio's two modes of work: first only GPS, second GPS/INS unit. On this picture it can be seen how much better is solution when receiver is using additionally INS unit (Kalarus M. et al., 2010). 


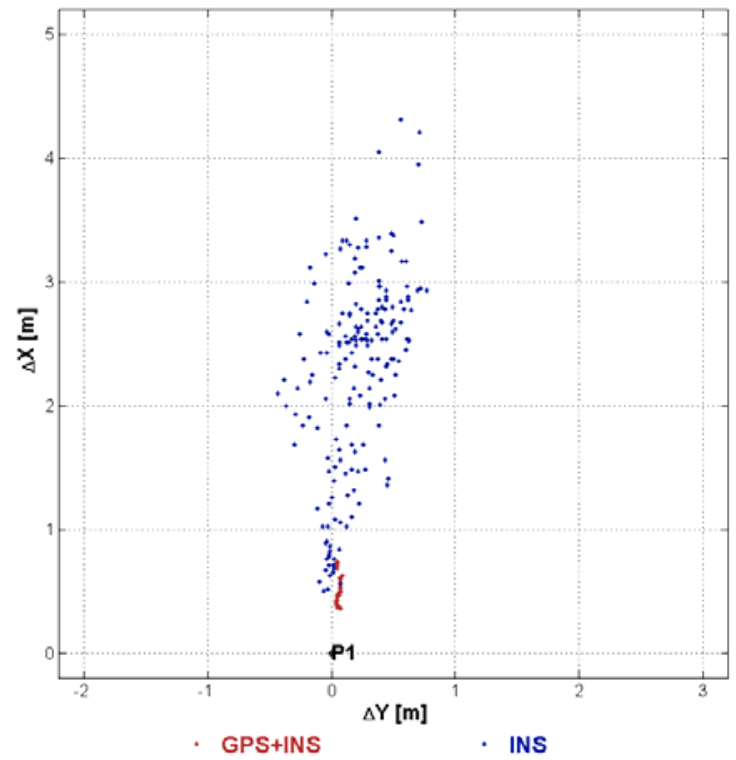

Fig. 8 Comparison of the distribution of measurements for Septentrio receiver working in two modes: GPS+INS and only GPS

\section{Measurements on $\mathrm{P} 2$ point}

The first test (only GNSS modules) took place on 26.04.2010 between 11:27 and 12:20 UTC. The measurement interval was $1 \mathrm{~s}$.

The second test took place on 15.01.2011 between 11:38 and 11:53 UTC. Septentrio and U-blox LEA6 were working with $1 \mathrm{~s}$ interval $(1 \mathrm{~Hz})-900$ epochs were registered. Xsens receiver was working with $10 \mathrm{~ms}$ interval $(100 \mathrm{~Hz})$ and that is the reason why the measurement time was shortened to 6 minutes (30000 epochs were registered) (Fig. 9).
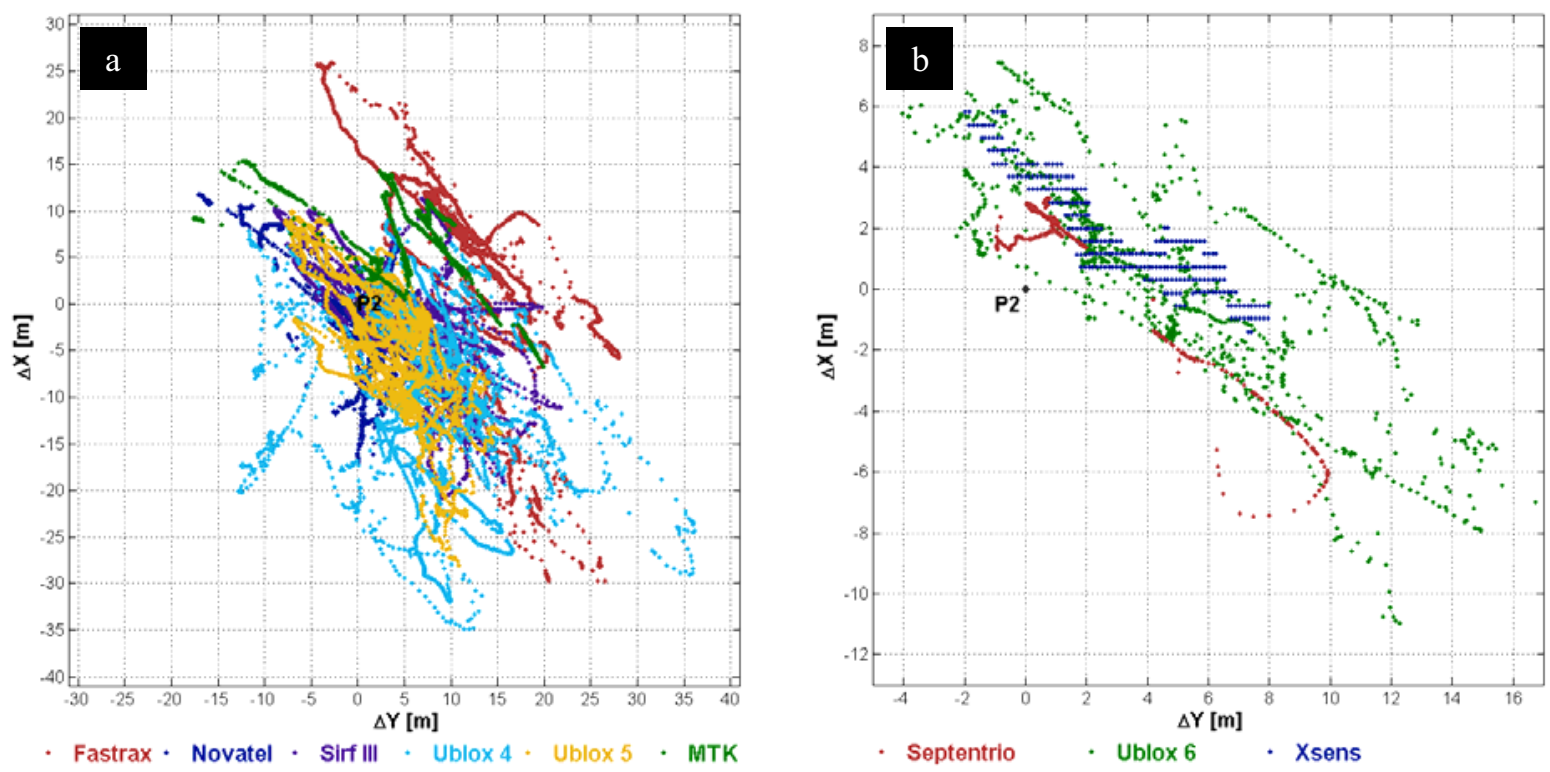

Fig. 9 Traces of the horizontal components of the localization solutions of the tested receivers with respect to reference position of point P2, (a) - first test, (b) - second test

During the first test the average number of used satellites was over 5, but Novatel and U-blox LEA4 observed on average only 4.1 and 4.5 satellites. That is why U-blox LEA4 receiver lost $1.54 \%$ of epochs and Novatel even $13.85 \%$. Besides the very low number of 
observed satellites, the accuracy and precision were additionally degraded because of multipath effect and poor satellite constellation geometry. Very clearly it can be seen in Fastrax and U-blox LEA4 measurements where shifts reached even over $10 \mathrm{~m}$. Only in Novatel receiver the bad satellite constellation parameters did not translate to the poor localization solution. Despite the worst DOP values Novatel provided the best results (shifts and standard deviation), but almost $14 \%$ measurements without position solution disqualify this receiver as a main one in Proteus system (Fig. 10).

Once again U-blox LEA5 achieved very good quality of position solution with the shifts (X, Y and Z) around $4 \mathrm{~m}$ and 100\% availability. All statistics are in table 6 .
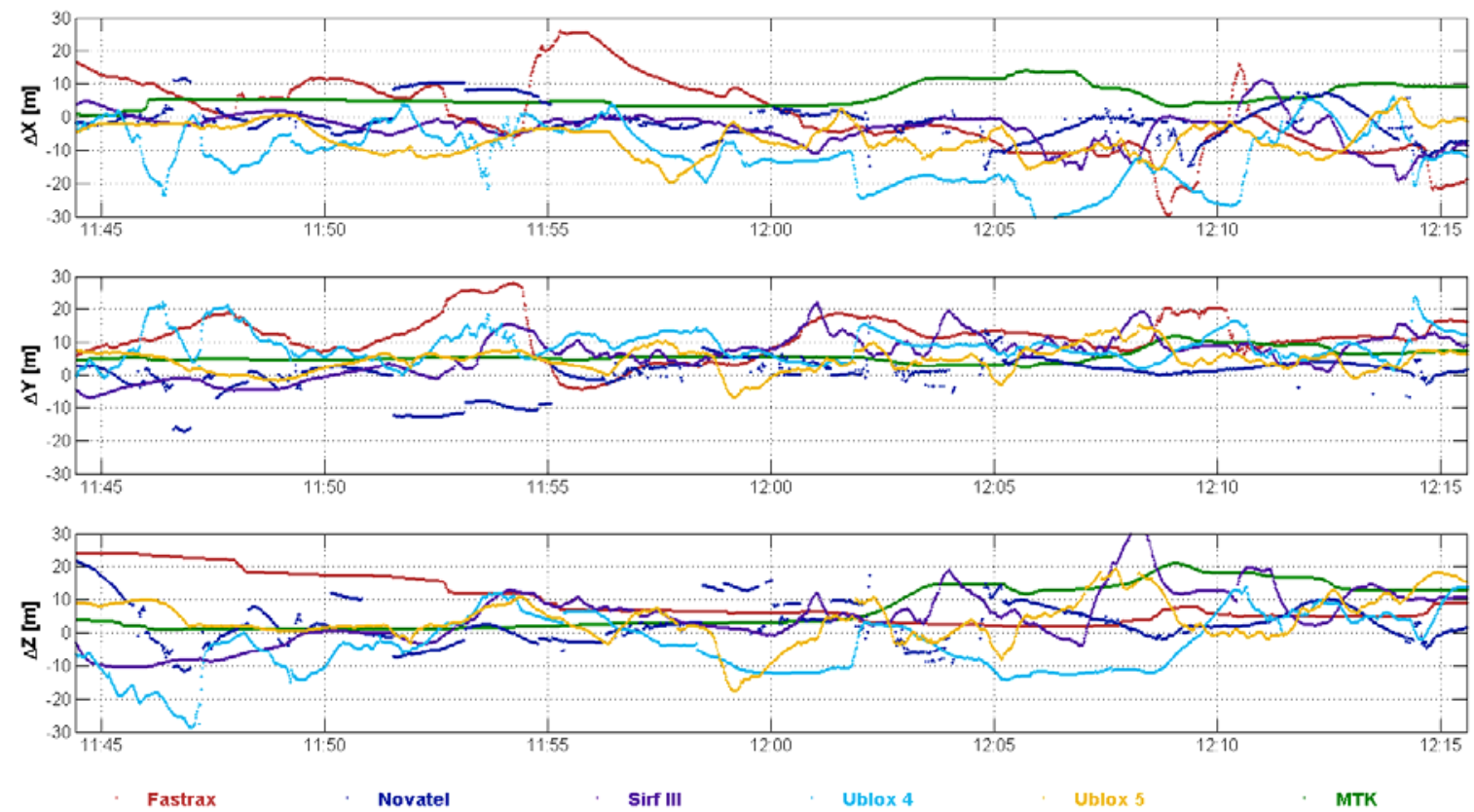

Fig. 10 Variability in time of the coordinates $X, Y, Z$ with respect to the reference position of point P2 during the first test

Table 2 Numerical comparison of the tested receivers on point P2 (values much better than rest are bolded)

\begin{tabular}{|c|c|c|c|c|c|c|}
\hline $\begin{array}{c}\text { Receiver } \\
\text { Parameter }\end{array}$ & Fastrax & MTK & Novatel & Sirf III & $\begin{array}{c}\text { U-blox } \\
\text { LEA4 }\end{array}$ & $\begin{array}{c}\text { U-blox } \\
\text { LEA5 }\end{array}$ \\
\hline $\begin{array}{c}\text { Epoch without } \\
\text { solution [\%] }\end{array}$ & 0.00 & 0.00 & 13.85 & 0.00 & 1.54 & 0.00 \\
\hline $\begin{array}{c}\text { Avg. number of } \\
\text { satellites }\end{array}$ & $\mathbf{6 . 7 1}$ & $\mathbf{6 . 8 1}$ & 4.12 & 5.03 & 4.52 & 5.13 \\
\hline DOP (avg): & 1.65 & 2.17 & 5.47 & 3.51 & 5.43 & 3.96 \\
\hline HDOP (avg): & $\mathbf{1 . 3 3}$ & $\mathbf{1 . 5 6}$ & 3.55 & 2.05 & 3.70 & 2.49 \\
\hline VDOP (avg): & $\mathbf{0 . 9 5}$ & 1.45 & 4.11 & 2.87 & 3.79 & 3.03 \\
\hline X Shift [m] & $\mathbf{- 0 . 7 0}$ & 6.26 & -2.27 & -2.92 & -11.05 & -5.06 \\
\hline Y Shift [m] & 11.72 & 4.54 & $\mathbf{0 . 6 7}$ & 4.74 & 8.72 & 4.06 \\
\hline Z Shift [m] & 11.80 & 7.50 & $\mathbf{1 . 1 5}$ & 6.14 & -2.10 & 4.07 \\
\hline $\begin{array}{c}\text { Std. deviation X } \\
{[m]}\end{array}$ & 11.23 & $\mathbf{4 . 1 6}$ & 5.51 & 6.77 & 9.34 & 6.88 \\
\hline $\begin{array}{c}\text { Std. deviation Y } \\
{[m]}\end{array}$ & 5.58 & 7.13 & $\mathbf{4 . 5 9}$ & 6.20 & 7.60 & $\mathbf{4 . 7 9}$ \\
\hline $\begin{array}{c}\text { Std. deviation Z } \\
\text { [m] }\end{array}$ & 8.18 & 7.31 & 7.98 & 7.29 & 14.90 & $\mathbf{6 . 9 7}$ \\
\hline
\end{tabular}


During the second test on P2 point all receivers achieved $100 \%$ availability of localization. The average number of used satellites was 6 .

Once again the best module was Septentrio with the $6 \mathrm{~m}$ maximum error and $4 \mathrm{~m}$ standard deviation ( 2 sigma parameter). Xsens achieved similar result with almost the same maximum error and standard deviation values. The characteristic parallel belts that can be seen in Xsens measurements (Fig. 9b) are caused by the too low resolution of the recording mode in the receiver. The U-blox LEA6 receiver with only GPS module inside gave solutions on quite good level: error $10 \mathrm{~m}$ and standard deviation $8 \mathrm{~m}$ (Fig. 11).
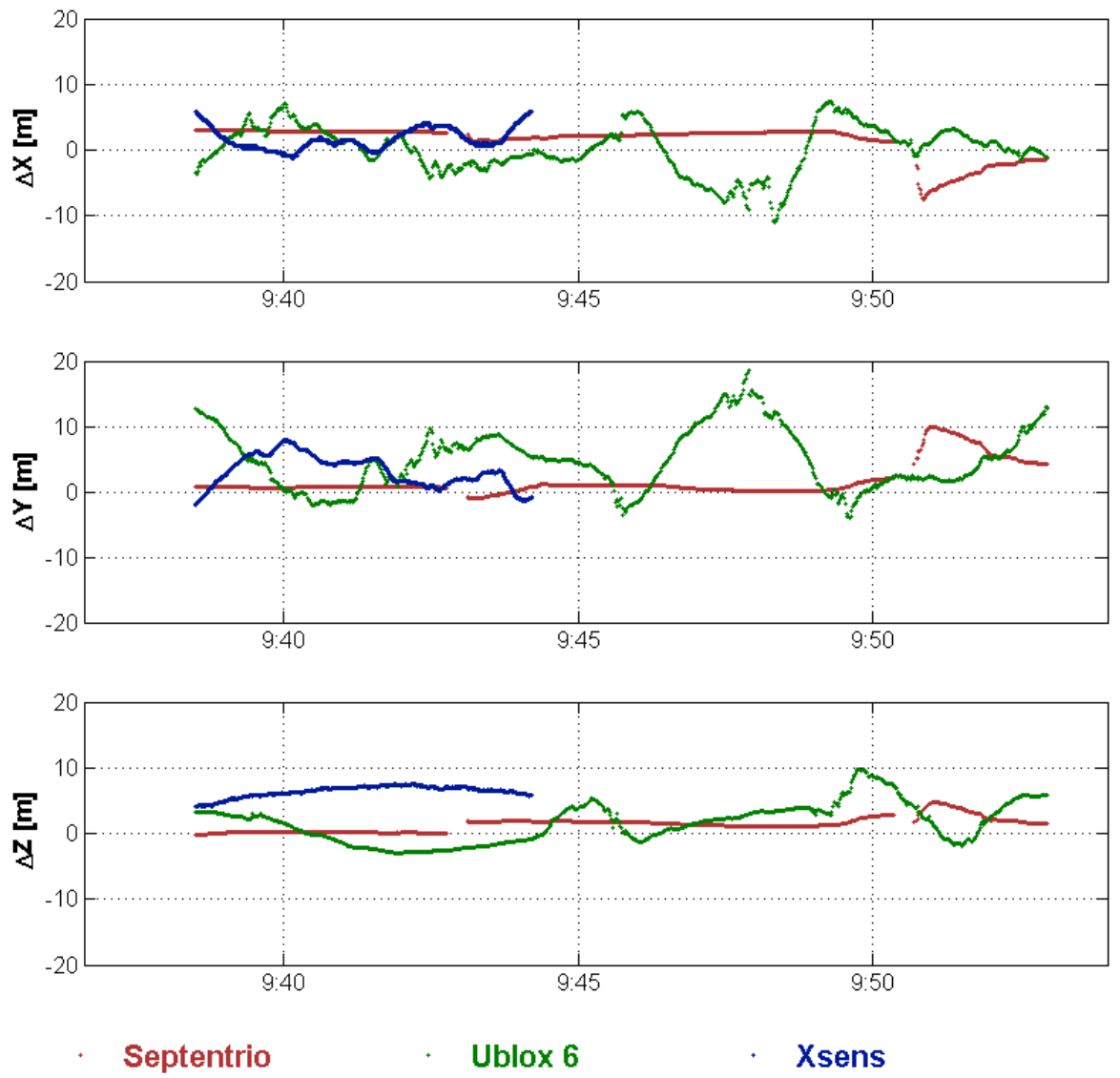

Fig. 11 Variability in time of the coordinates $\mathrm{X}, \mathrm{Y}, \mathrm{Z}$ with respect to the reference position of point $\mathrm{P} 2$ during the second test

\section{Kine matic tests}

\section{Test in SRC of PAS area}

The path of the test led by open sky area, field with many trees and along high building. The duration of test was 45 minutes, the measurement interval was $1 \mathrm{~Hz}$ (Fig.12). 

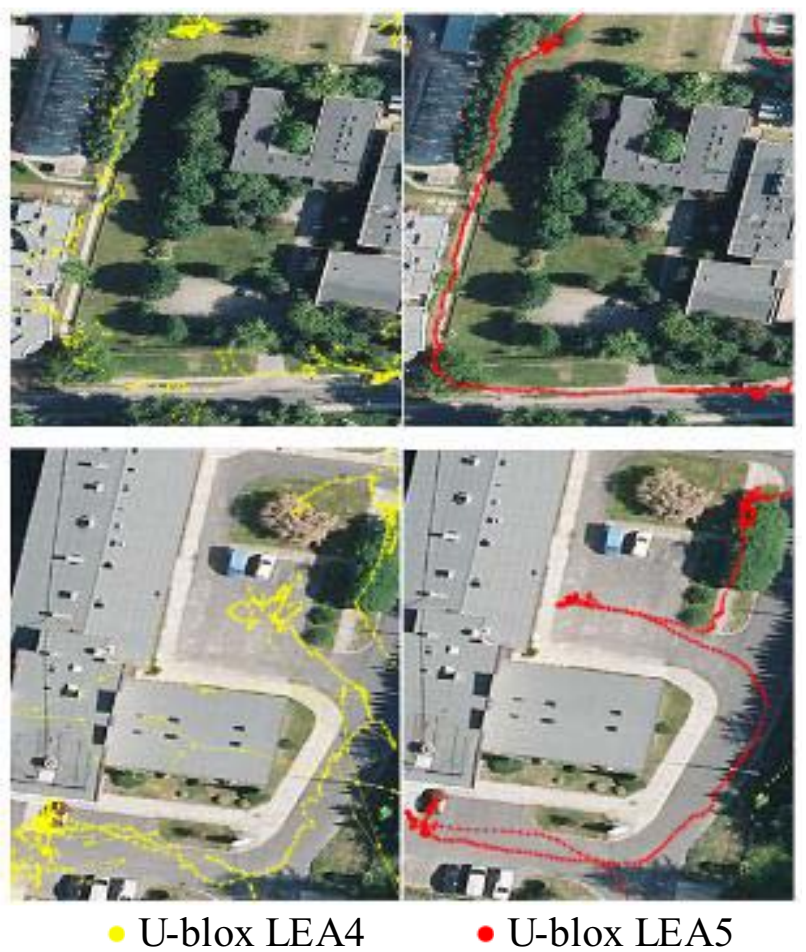

Fig. 12 Comparison of the worst and the best GNSS module during the kinematic test in SRC of PAS area

\section{Street test}

In this test special platform was prepared and installed on the roof of the car. The six receivers which took part in the first static test were mounted on this platform (table 2). The duration of the measurements was around $2 \mathrm{~h}$ with the frequency of $1 \mathrm{~Hz}$. The way led through wide street (almost open sky conditions), urban canyon and also multi-storey car park. Once again the best receivers were U-blox LEA5 and Sirf Star III. Novatel gave high quality solutions, but it needed very good satellite constellation conditions (entrance to the urban canyon or forest caused big degradation or even lack of localization solution).

In the figure 13 the measurements from street kinematic tests are visible. The upper left picture presents measurements made during drive through local road, under bridge, and three-lane highway. The upper right picture presents measurements made during drive through suburbs roads with houses and singular trees around. The lower left picture presents measurements made during drive through dense forest. The lower right picture presents measurements made during drive through urban canyon, the housing estate ( $\sim 6$ floors) with very narrow roads (3- 4 m width). 


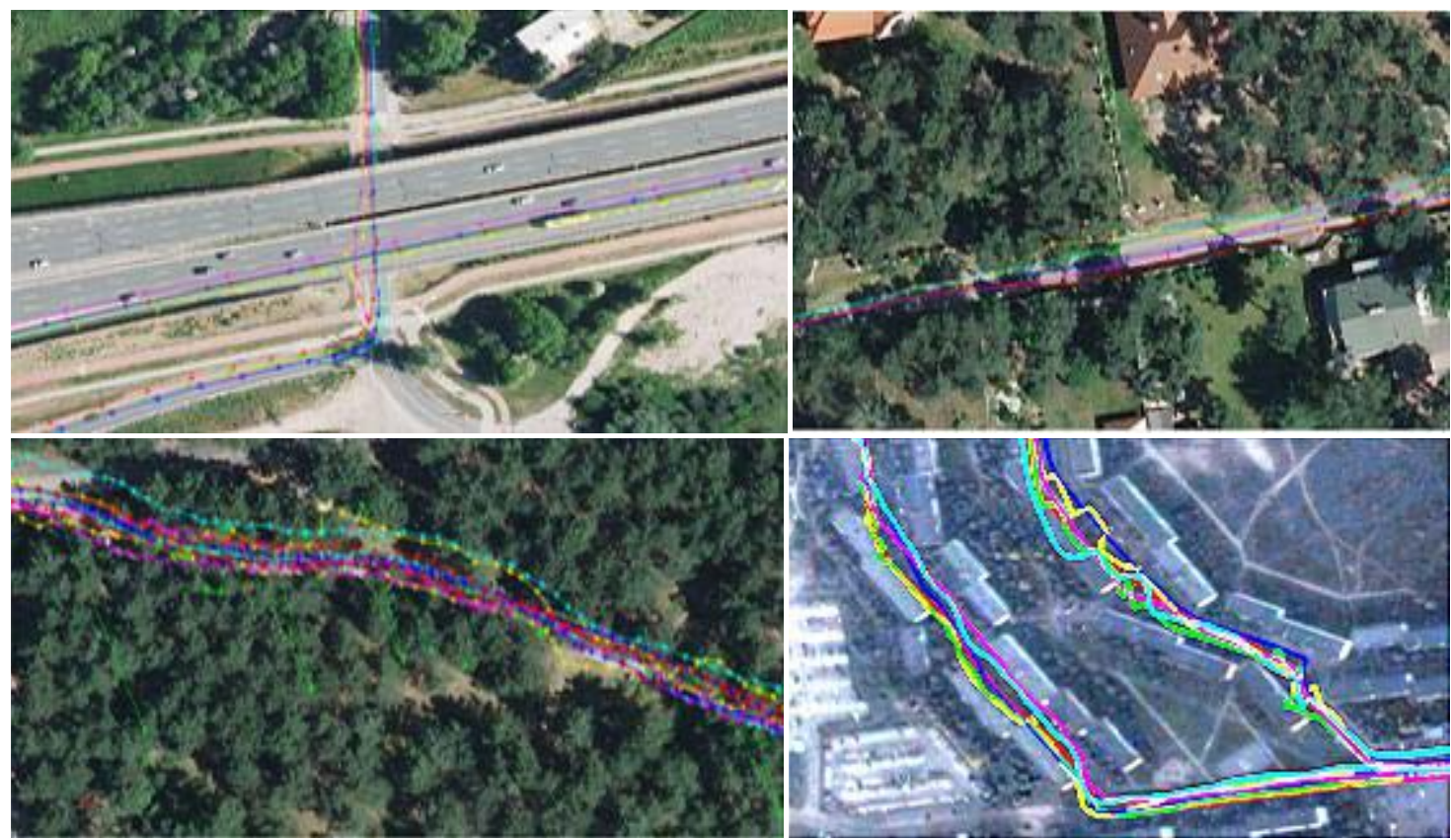

- Fastrax • Novatel • Sirf Star III • U-blox LEA4 • U-blox LEA5 • MTK

Fig. 13 Comparison of the all GNSS receivers under different environmental conditions

\section{Indoor (GNSS)}

Indoor test took place in SRC PAS building on the two top floors and the staircase (Fig. 14). For this case only 4 the most sensitive GNSS receivers were chosen: MTK, Fastrax, Sirf Star III and U-blox LEA5 (Table 2).

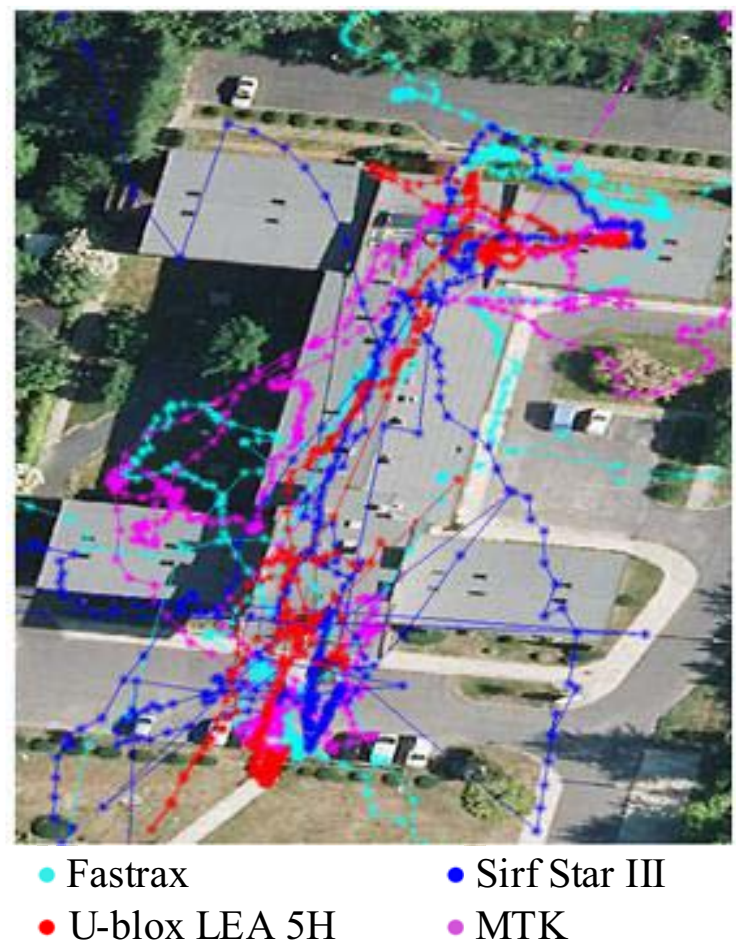

Fig. 14 Comparison of the four receivers during the test inside the SRC of PAS building 


\section{Terrain tests}

Second part of kinematic tests took place in January 2011. In this measurement three receivers were used: Septentrio (GPS/INS), Xsens (GPS/INS) and U-blox LEA6 (only GPS).

All receivers were placed on a mobile platform, $30 \mathrm{~cm}$ above the ground and were connected to a mobile battery. The test path was well defined on the SRC PAS area. Two characteristic places on the test route were: short entrance to the building (no satellite visibility), passing under fire stairs (steel construction).

The test conditions were repeated in order to show the GNSS receivers' behavior in the same environment but in different satellite constellation. This test gave us comparison of these 3 receivers' quality to the previous ones'.

\section{Septentrio receiver}

Three independent tests show very good measurements repeatability.
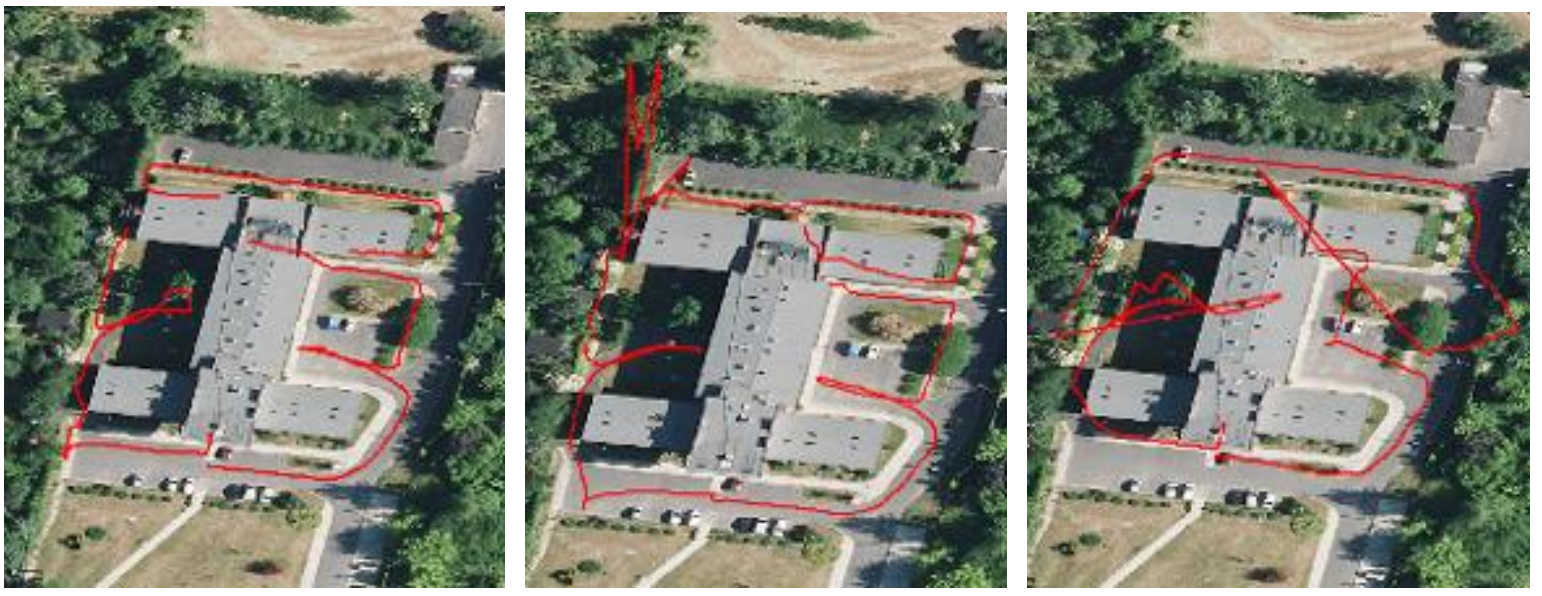

Fig. 15 Results of the kinematic test on 7, 10 and 11 May 2011 achieved by the Septentrio module AsteRX $2 \mathrm{i}$

Test of $7^{\text {th }}$ May 2011 was the best one if we considered the accuracy, but in two places there were no solutions (availability around 95\%).

During the test of $10^{\text {th }}$ May 2011 the receiver lost position solution in one place $(97 \%$ of availability). The Septentrio receiver showed very high accuracy of solution, only in very thought terrain (passing under the fire stairs) the solution quality was poor.

In $11^{\text {th }}$ May 2011 the receiver provided $100 \%$ of availability. But whole test was a little worse in accuracy.

The Septentrio receiver proved to be the best of all tested modules. It provided sub-meter accuracy in the kinematic mode. The receiver gives also the very high precision of measurement (thanks to the use of the integrated GPS/INS module). However the high quality solutions could be obtained only with good satellite conditions (Fig. 15). After 10 second without satellites visibility the receiver switched off because of the very big position error.

\section{U-blox LEA6 receiver}

The tests of U-blox LEA6 receiver proved the best repeatability of measurements of both: availability and accuracy. Average availability was on $90-95 \%$ level, no solutions were 
available after entrance to the building. The accuracy was on GPS standard level (in most time 2-3 meters) (Fig. 16).
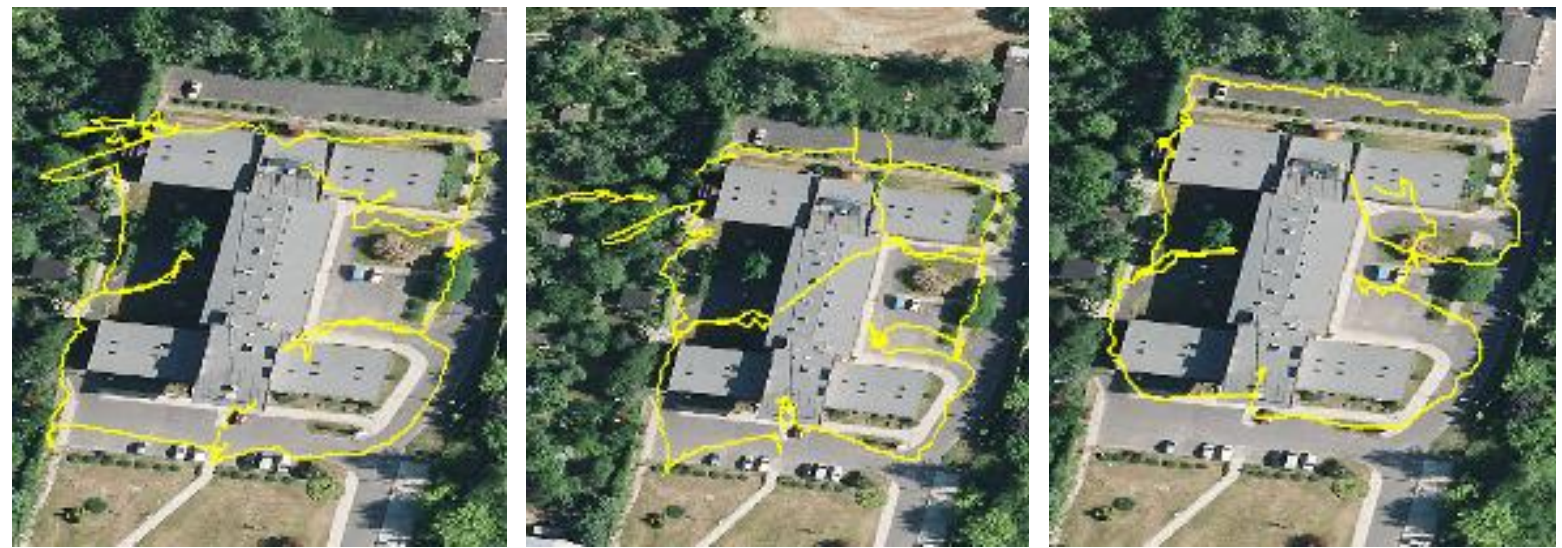

Fig. 16 Results of the kinematic test on 7, 10 and 11 May 2011 achieved by the U-blox LEA6 module

\section{Xsens MTI-G receiver}

First two test (7 and 10 of May 2011) are incomplete. In first case the receiver lost the position after entrance to the building and did not return to normal work. In second case the receiver worked properly but there were some problems with the communication between Xsens and laptop and the data were not saved. During third test the receiver obtained $100 \%$ of availability. The accuracy was not as good as in Septentrio module but the precision was on similar level (this is the effect of using the integrated GPS/INS module) (Fig. 17).
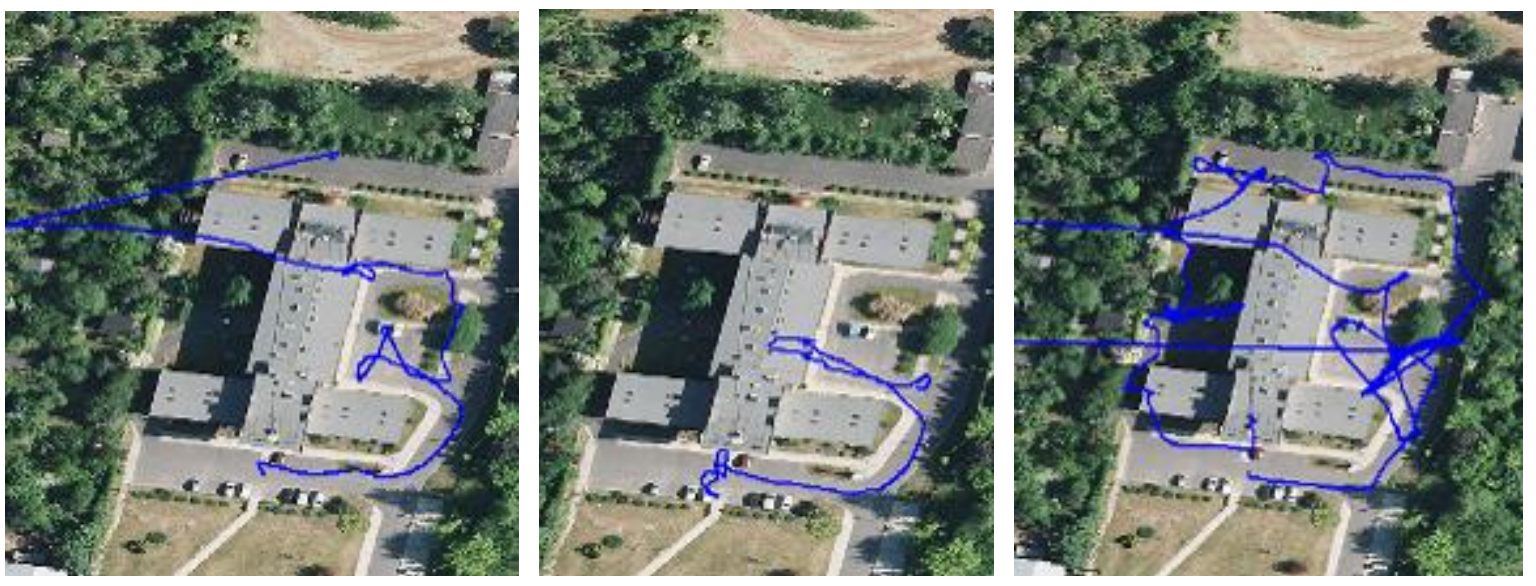

Fig. 17 Results of the kinematic test on 7,10 and 11 may 2011 achieved by the Xsens MTI-G module

\section{Indoor tests}

During indoor tests the usefulness of integrated GPS/INS modules was investigated. Unfortunately both Septentrio and the Xsens receivers, after losing the GPS signal (no satellite visibility more than 10 seconds), lost the possibility to determine position. Only very high sensitivity GNSS receiver U-blox LEA6 obtained the position. 

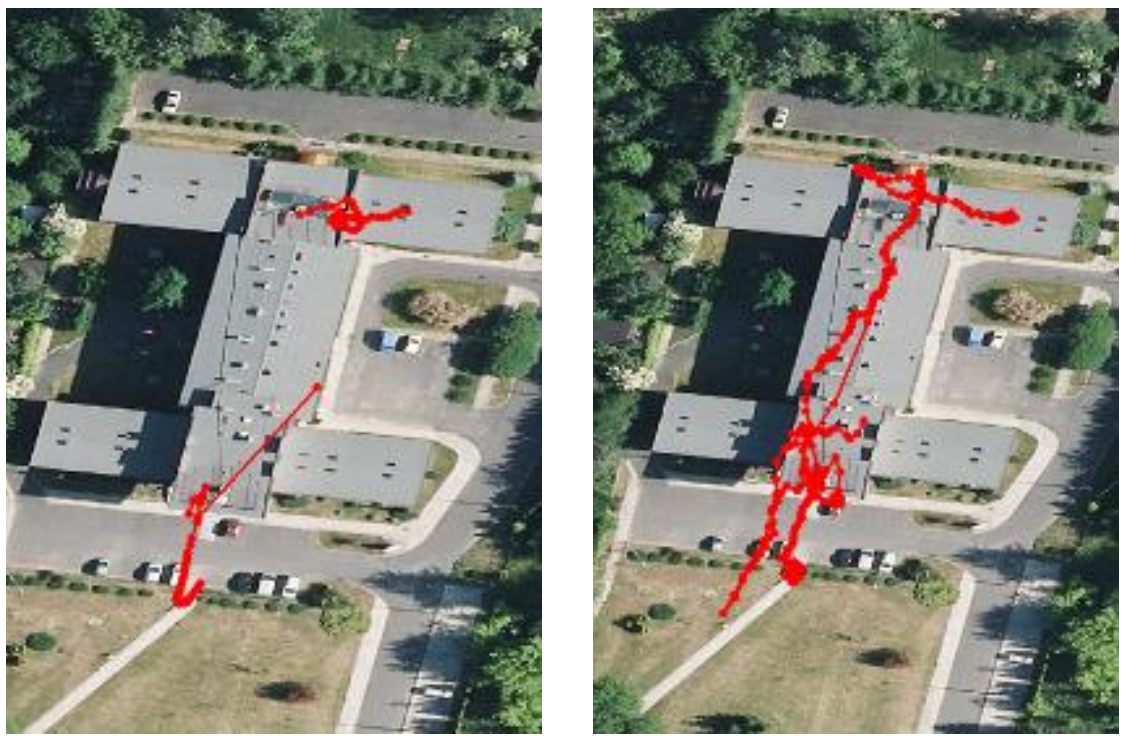

Fig. 18 Receiver U-blox LEA6 during the test inside the building upper tier (left), lower tier (right)

The results of kinematic tests confirmed that the right choice of GNSS receiver was done. The U-blox LEA6 was able to navigate even inside a building (Fig. 18).

\section{CONCLUSIONS}

The test results show that the differences between particular chips (even between those, which are similar in technical description) could be very sufficient. The differences in accuracy and precision reach even several hundred percent.

Highly sophisticated GNSS modules (e.g. Novatel OEMV-3G) working in SPS GPS mode (without additional options like GLONASS or EGNOS) in normal observation conditions (static tests on point P1 or some parts of kinematic measurements) give similar results to the best simple, small GNSS chips (like U-blox LEA5).

In difficult circumstances (partly obstructed horizon, big multipath effect) the big, technologically advanced modules produce high quality position solution (accuracy and precision), but the availability of the solution is not the best (on point P2 Novatel availability was below 90\%). The embedded algorithms are working correctly and mitigate the multipath effect but only to some threshold value. When the receiver assesses that the effect is too high it prefers producing no solution to producing bad solution. In this field the way of working the simple, small GNSS chips is different: there is no such verification of solution quality and, as long as they observe at least four satellites and can determine position solution even with error of 30-40 meters (e.g. U-blox LEA4 on point P2).

Usage of GNSS chip integrated with INS module assures very good results. During the tests (static and kinematic) in normal conditions (at least four satellites were available) the quality of positioning solution increased. The location solution was significantly more accurate, precise and stable (without any peaks). Especially during kinematic tests when the observation conditions were changing relatively fast (satellite constellation, multipath, driving under bridges or through tunnels). In such conditions the integrated module GNSS/INS worked very well. Unfortunately after lost GNSS solution the GNSS/INS module did not work properly and after few seconds the location solution gave an error of tens of meters. That is why the GNSS/INS module is not a good idea for indoor positioning. 
Tests have shown that better (but of course not perfect) solution for indoor applications are high sensitivity GNSS chips.

The key role in the GNSS/INS positioning quality plays the integration algorithm and that is why two devices with exactly the same INS module and similar GNSS chips but various inner algorithms were working totally differently (Septentrio and Xsens).

Such results of the test have allowed to select following receivers for the elements of the Proteus system:

- For firefighters, where low power consumption and high availability in poor conditions is needed, the best solution will be small and simple but high sensitivity GNSS module U-blox LEA5 (in the near future U-blox LEA6). The U-blox modules are pin-compatible what is additional bonus for the project.

- For mobile robots localization, where good quality of solution + orientation parameters are needed, the best choice will be Septentrio.

- For Proteus cars, where is no power and size limitation, the best solution will be Novatel OEMV-3G, the multi-constellation (GPS + GLONASS) receiver with EGNOS option, the MGL SP-2 3-axis avionic compass and the Gemac IS2A60P20 inclination sensor.

\section{Acknowledgments}

The project is a cooperation of 7 Polish scientific institutes: Industrial Research Institute for Automation and Measurements, Space Research Centre PAS, Scientific and Research Centre for Fire Protection, Institute of Electronic Materials Technology, Poznan University of Technology, Warsaw University of Technology, Military University of Technology.

The Project is co-financed by the European Regional Development Fund within the framework of the 1. priority axis of the Innovative Economy Operational Programme, 2007-2013.

\section{REFERENCES}

Brzostowski K., Foks-Ryznar A., Sitek P., Zdunek R. (2010). Ocena przydatności wybranych modułów GNSS na potrzeby lokalizacji elementów systemu PROTEUS, Geodeta. Magazyn Geoinformacyjny, Vol.12 (187), 12-17.

Darakchiev R., Sitek P., Brzostowski K., Foks-Ryznar A., Kalarus M., Zdunek R. (2010), Moduły lokalizacji oraz testy chipów GNSS dla elementów systemu PROTEUS. Elektronika - Konstrukcje, Technologie, Zastosowania, Vol.11, 122-126.

Fastrax UP500 technical description http://www.fastraxgps.com

Kalarus M., Sitek P., Brzostowski K., Foks-Ryznar A., Darakchiev R. (2010). Analiza możliwości zastosowania sensorów inercjalnych MEMS w projekcie PROTEUS. Elektronika - Konstrukcje, Technologie, Zastosowania, Vol.11, 127-129.

Modulestek Sirf Star III technical description http://www.datasheets.org.uk/Modulestekdatasheet.html

NovAtel OEMV-3G technical description http://www.novatel.com/

MTK Mediatek technical description http:/www.nghobbies.com/cart/datasheet/GTGPSdatasheet.pdf

Septentrio AsteRx 2i technical description http://www.septentrio.com/ 
Sitek P., Brzostowski K., Darakchiev R., Foks-Ryznar A., Kalarus M., Zdunek R. (2011). Location Modules for Elements of Mobile System for Counterterrorism and Rescue Operations "PROTEUS". Uzbrojenie conference materials, Pułtusk 2011

U-blox LEA 4P technical description

U-blox LEA 5H technical description http://www.u-blox.com/

U-blox LEA 6H technical description http://www.u-blox.com/

XSens MTi-G technical description http://www.Xsens.com/

Received: 2012-05-25,

Reviewed: 2012-06-28, by J. Januszewski,

Accepted: 2012-06-29. 